\title{
Familial opsonization defect associated with fatal infantile dermatitis, infections, and histiocytosis
}

\author{
H. SCOTT, E. J. MOYNAHAN, R. A. RISDON, B. A. M. HARVEY, and J. F. SOOTHILL \\ From the Departments of Dermatology and Morbid Anatomy, The Hospital for Sick Children, and \\ the Department of Immunology, Institute of Child Health, London
}

Scott, H., Moynahan, E. J., Risdon, R. A., Harvey, B. A. M., and Soothill, J. F. (1975). Archives of Disease in Childhood, 50, 311. Familial opsonization defect associated with fatal infantile dermatitis, infections, and histiocytosis. Members of four generations of a family had a defect of serum opsonization for yeast phagocytosis consistent with dominant inheritance. 2 were healthy, one had chronic osteomyelitis, and the fourth developed a fatal illness in infancy characterized by exfoliative dermatitis, diarrhoea, multiple bacterial infections, and failure to thrive, which resembled the two previously reported cases with this opsonization defect. At necropsy the infant also had lymphoid depletion, which was possibly secondary, and massive histiocytic infiltration.

We report the illness of a child who presented with exfoliative dermatitis, diarrhoea, and frequent infections. She subsequently died of a disease diagnosed at necropsy as Letterer-Siwe disease, in view of extreme histiocytic inflltration. One member each of four generations of the family had a defect of serum opsonization, similar to that described by Miller et al., (1968) and Jacobs and Miller (1972) as presenting in this way. The defect in this family was associated not only with this fatal illness, but with chronic osteomyelitis and with excellent health.

\section{Case history}

The patient, the first child of healthy unrelated parents, thrived for the first month after a normal term delivery (birthweight $3.6 \mathrm{~kg}$ ). She was breast fed for 2 weeks and then continued on a cow's milk preparation. At 4 weeks of age she developed 'cradle cap' and an erythematous rash in the napkin area and flexures. This initially responded to topical steroids but later relapsed so that at 8 weeks of age she was admitted to All Saints Hospital, Chatham, with a generalized 'seborrhoeic dermatitis' which was secondarily infected with Staphylococcus aureus. She was feeding poorly with occasional vomiting and had lost weight. The rash deteriorated despite topical and systemic steroids and antibiotics. She developed profuse diarrhoea and required I.V. fluids. On reintroduction of milk feeds the diarrhoea returned and she was transferred to this hospital.

Received 17 September 1974.
At 11 weeks she was wasted, weighing $3 \cdot 2 \mathrm{~kg}$, less than her birthweight. Her entire body surface was covered with an erythematous eruption which was moist, fissured, and secondarily infected in the flexures and on the extremities. There was slight generalized oedema, crusting of the scalp, the hair was sparse, and the nails thin and brittle. There was generalized lymphadenopathy. The liver and spleen were not enlarged. She was treated with emulsifying ointments, local hydrocortisone and systemic erythromycin, but the dermatitis persisted with irregular 3-8 day cycles of exacerbations and remissions with desquamation. Diarrhoea was provoked by both lactose and sucrose-free milks, but she tolerated feeds based on chicken, glucose, and Prosparol. She was also given I.V. fluids, stored plasma, and stored citrated blood soon after admission to correct anaemia and hypoalbuminaemia. She failed to gain weight and continued to have intermittent fever (35$\left.39^{\circ} \mathrm{C}\right)$. Repeated blood cultures were sterile, but at 13 weeks of age she developed a small staphylococcal scalp abscess and, 2 weeks later, septic arthritis of the left hip and osteomyelitis of the head of the right humerous. Pus aspirated from both these sites yielded Staph. aureus of similar antibiotic sensitivities. She was given parenteral cloxacillin and fucidic acid and a blood transfusion. A diagnosis of Miller's opsonizing defect was confirmed by demonstration of defective opsonization for yeast phagocytosis by her serum and that of her relatives.

Investigations. The techniques used are routine, except for the opsonization test (Miller et al., 1968). Patient's serum, diluted in saline, was incubated at $37^{\circ} \mathrm{C}$ for 30 minutes (continuous mixing) with suspen- 
TABLE I

Haematological and immunological data on patient at different stages in her illness

\begin{tabular}{|c|c|c|c|c|}
\hline Test & $\begin{array}{c}\text { On } \\
\text { admission }\end{array}$ & $\begin{array}{l}\text { When } \\
\text { with } \\
\text { infected } \\
\text { bones }\end{array}$ & $\begin{array}{c}\text { When } \\
\text { clinically } \\
\text { improved } \\
\text { on plasma } \\
\text { treatment }\end{array}$ & $\begin{array}{c}\text { During } \\
\text { terminal } \\
\text { illness }\end{array}$ \\
\hline $\begin{array}{l}\text { Hb }(\mathrm{g} / \mathrm{dl}) \\
\text { Neutrophils } / \mathrm{mm}^{3} \\
\text { Lymphocytes } / \mathrm{mm}^{3} \\
\text { Eosinophils } / \mathrm{mm}^{3} \\
\text { Platelets } / \mathrm{mm}^{3} \\
\text { IgG (IU } / \mathrm{ml}) \\
\text { IgA (IU } / \mathrm{ml}) \\
\text { IgM (IU } / \mathrm{ml}) \\
\text { Mean yeasts } \% \text { of control } \\
\text { neutrophil }\end{array}$ & $\begin{array}{c}10 \cdot 8 \\
6400 \\
4600 \\
230 \\
\text { Normal } \\
25 \\
<10 \\
276 \\
-\end{array}$ & $\begin{array}{c}8 \cdot 7 \\
12100 \\
2800 \\
0 \\
\text { Normal } \\
64 \\
13 \\
132 \\
74\end{array}$ & $\begin{array}{c}11 \cdot 6 \\
3300 \\
8580 \\
1600 \\
\text { Normal } \\
72 \\
66 \\
168 \\
91\end{array}$ & $\begin{array}{r}11 \cdot 5 \\
12500 \\
72000 \\
5400 \\
13000 \\
58 \\
12 \\
96 \\
-\end{array}$ \\
\hline
\end{tabular}

sions of normal human leucocytes (prepared by Dextran sedimentation) and heat-killed baker's yeast. The leucocytes were separated by slow centrifugations, resuspended, and smears were prepared and stained with May-Grünwald/Giemsa. 200 polymorphonuclear leucocytes were examined, and the number of yeast particles in each was counted. Samples were studied in duplicate; these agreed well. Results were expressed as median and mean values of yeasts/neutrophil, and as patient mean/parallel control mean $\%$. The results of this and some other tests at different stages of her disease are shown in Table $I$. She had a normal white blood count on admission but developed neutrophilia with the bone infections. This settled, but she developed lymphocytosis and eosinophilia, with thrombocytopenia in her terminal illness. IgM was raised at first and IgG and IgA were detected. Serum albumin remained low. Normal values were obtained for $\mathrm{C} 3$, quantitative and qualitative NBT test, and polymorph bacterial phagocytosis and killing. Lymphocyte PHA response was measured late in the course of her illness, the severity of which may have influenced the reaction: a low but significant response was found $\left({ }^{3} \mathrm{H}\right.$ thymidine uptake: stimulated counts 693, unstimulated 163; control 6630 and 45). Low titres of anti-cytomegalovirus (8) and anti-Epstein-Barr (4) virus were detected after plasma had been infused, but not of a wide range of other antiviral antibodies. Bone marrow taken shortly before death was normally reactive, with plasma cells and reticulum cells prominent, and normal numbers of lymphocytes. No abnormal cells were seen.

The findings of yeast phagocytosis were consistently lower than parallel control, but we have little control data for ill children and all the specimens were taken after some plasma had been infused, so the parents were investigated to confirm the diagnosis.

Family studies. The patient was the first child of unrelated healthy parents. Her father and some of his family have had mild atopy but were otherwise healthy. Her mother's family had several unusual features. The mother, an only child, was healthy, as was the patient's maternal grandmother and most of her 8 sibs. The maternal grandfather, who also had no sibs, had had chronic discharging osteomyelitis of the tibia, after multiple episodes of osteomyelitis affecting several bones, at the age of 10 years. His mother was well, but one of her 2 brothers developed osteomyelitis after a compound fracture, which led to amputation at 39 years, and the other died of septicaemia at 30 years. These illnesses occurred before antibiotics were available, and there was no history of skin disease or infection in infancy. Apart from the maternal grandfather's chronic osteomyelitis, all the relatives were well at the time of study.

Serum opsonization for yeast phagocytosis was deficient in the mother and the maternal grandfather (Table II). The values were considerably lower than those of the parallel controls, and fell well outside the mean -2SD for 44 healthy adults (mean 4.40, SD 1.01), though this mean was reduced and SD increased by one exceptional value $(0 \cdot 06)$. Duplicate determinations on each sample agreed well; repeated samples from the mother and repeated tests on each serum from each affected person consistently gave values less than those of parallel controls. The maternal great grandmother's serum also gave values well below the parallel control, but the number of yeasts phagocytosed does not fall below mean -2SD for our healthy samples; there is considerable inter-batch variation in this determination, so we think that she is probably also affected. The father, great-grandfather, and great-uncle gave values similar to their controls. The mother and grandfather had raised serum IgG and IgM concentrations and normal or high ASO and isoagglutinin activity. The grandfather's blood counts and polymorph bacterial phagocytosis and killing were normal.

Total haemolytic complement, and complement components $\mathrm{C} 3, \mathrm{C} 4, \mathrm{C} 5, \mathrm{C} 6$, and $\mathrm{C} 7$ were determined on the sera of the patient, her mother, and maternal grandfather. Results (Table III) are expressed as titres, or as \% of parallel serum from a healthy subject. All the values for individual components are comparable with the healthy subjects The patient's mother had 
TABLE II

Opsonization for yeast phagocytosis by normal polymorphs and immunoglobulin concentrations in the serum of 3 antecedent generations of the patient

\begin{tabular}{|c|c|c|c|c|c|c|}
\hline & \multicolumn{3}{|c|}{ Yeasts/polymorphs } & \multicolumn{3}{|c|}{ Ig $(\mathbf{I U} / \mathrm{ml})$} \\
\hline & Mean & Median & $\frac{\text { Mean }}{\text { control mean }} \%$ & G & $\mathbf{A}$ & $\mathbf{M}$ \\
\hline $\begin{array}{l}\text { Mother } \\
\text { Father } \\
\text { Maternal grandfather } \\
\text { Maternal great-grandmother } \\
\text { Maternal great-grandfather } \\
\text { Maternal great-great uncle }\end{array}$ & $\begin{array}{l}1 \cdot 6 \\
4 \cdot 5 \\
1 \cdot 4 \\
3 \cdot 0 \\
4 \cdot 1 \\
4 \cdot 5\end{array}$ & $\begin{array}{l}1 \\
5 \\
1 \\
3 \\
5 \\
5\end{array}$ & $\begin{array}{r}32 \\
98 \\
24 \\
71 \\
98 \\
107\end{array}$ & $\begin{array}{l}200 \\
156 \\
236 \\
168 \\
188 \\
184\end{array}$ & $\begin{array}{r}80 \\
156 \\
136 \\
96 \\
640 \\
72\end{array}$ & $\begin{array}{r}576 \\
148 \\
240 \\
72 \\
96 \\
84\end{array}$ \\
\hline
\end{tabular}

TABLE III

Haemolytic complement titration

\begin{tabular}{|c|c|c|c|c|c|c|}
\hline & $\begin{array}{c}\text { Total (complement) } \\
\text { titre }\end{array}$ & C3 titre & C4 titre & C5 (\%) & C6 (\%) & C7 (\%) \\
\hline $\begin{array}{l}\text { Patient } \\
\text { Mother } \\
\text { Maternal grandfather } \\
\text { Healthy subject }\end{array}$ & $\begin{array}{l}360 \\
648 \\
488 \\
650\end{array}$ & $\begin{array}{l}800 \\
800 \\
800 \\
800\end{array}$ & $\begin{array}{r}800 \\
800 \\
1600 \\
800\end{array}$ & $\begin{array}{r}92 \\
114 \\
120 \\
100\end{array}$ & $\begin{array}{r}116 \\
85 \\
109 \\
100\end{array}$ & $\begin{array}{r}91 \\
104 \\
111 \\
100\end{array}$ \\
\hline
\end{tabular}

total complement activity similar to that of the control, but both the patient and her grandfather gave lower values Neither the grandfather's value nor, because of her age, illness, and treatment, that for the patient is definite evidence of primary abnormality.

Progress and treatment. The patient was given intravenous fresh plasma, $100 \mathrm{ml}$ once a week and later $50 \mathrm{ml}$ twice a week, with continued systemic antibiotics. She improved over the next 6 weeks with gradual weight gain to $3.7 \mathrm{~kg}$, normal temperature, and no overt infections apart from oral thrush which was controlled by nystatin. The skin eruption improved but not in the dramatic fashion after each plasma transfusion reported by Jacobs and Miller (1972). A small increase of yeast opsonization was noted with 2 of the infusions (mean yeasts/leucocyte $4 \cdot 7-4 \cdot 9$ and $4 \cdot 0-4 \cdot 8$ ), in spite of the fact that the initial value was still relatively high, presumably after the previous infusion.

At 23 weeks she developed nasal discharge and consolidation of the upper lobe of the right lung. Over the following weeks there was further massive enlargement of the lymph nodes, particularly in the axillae and groins, with moderate enlargement of the liver and spleen. She lost weight again, became anaemic, and developed extreme lymphocytosis, eosinophilia, and thrombocytopenia, with a few petechial haemorrhages in the skin. The possibility of graft versus host disease was considered, and male lymphocytes were sought in her blood; none were found, but much of the plasma had been from a female donor. Bacteria, Gram-nega- tive and -positive, were grown from the skin, nose, and pharynx, but despite intense antibiotic treatment bronchopneumonia ensued, and she died with a $\beta$ haemolytic streptococcal septicaemia at 31 weeks of age.

Necropsy. There was generalized oedema and the skin was scaling. The head was devoid of hair. There was generalized enlargement of lymph nodes, which were discrete, firm, homogeneous, and pinkish-white. The liver and spleen were enlarged, weighing 302 and $80 \mathrm{~g}$, respectively. Both lungs were congested, with scattered areas of consolidation, collapse, and compensatory emphysema throughout. The thymus was very small $(<1 \mathrm{~g})$ and was situated entirely above the innominate vein. The tonsils were both palpable.

Histological examination of most of the enlarged lymph nodes showed almost complete effacement of the normal nodal architecture by sheets and compact masses of histiocytic cells with ill-defined margins, abundant cytoplasm, and round or oval vesicular nuclei (Fig. 1). Others showed extreme cortical and paracortical lymphoid depletion, but some follicles were seen. Most of the cells were reticular cells. The thymus had a lobular pattern with poor corticomedullary demarcation, and was composed largely of reticular cells with very few lymphocytes superficially like those seen in severe combined immunodeficiency (Berry, 1970), but on serially sectioning the gland occasional Hassall's corpuscles were seen (Fig. 2). The skin was infiltrated by histiocytic cells especially in the upper dermis (Fig. 3). The bone marrow and spleen pulp were extensively 


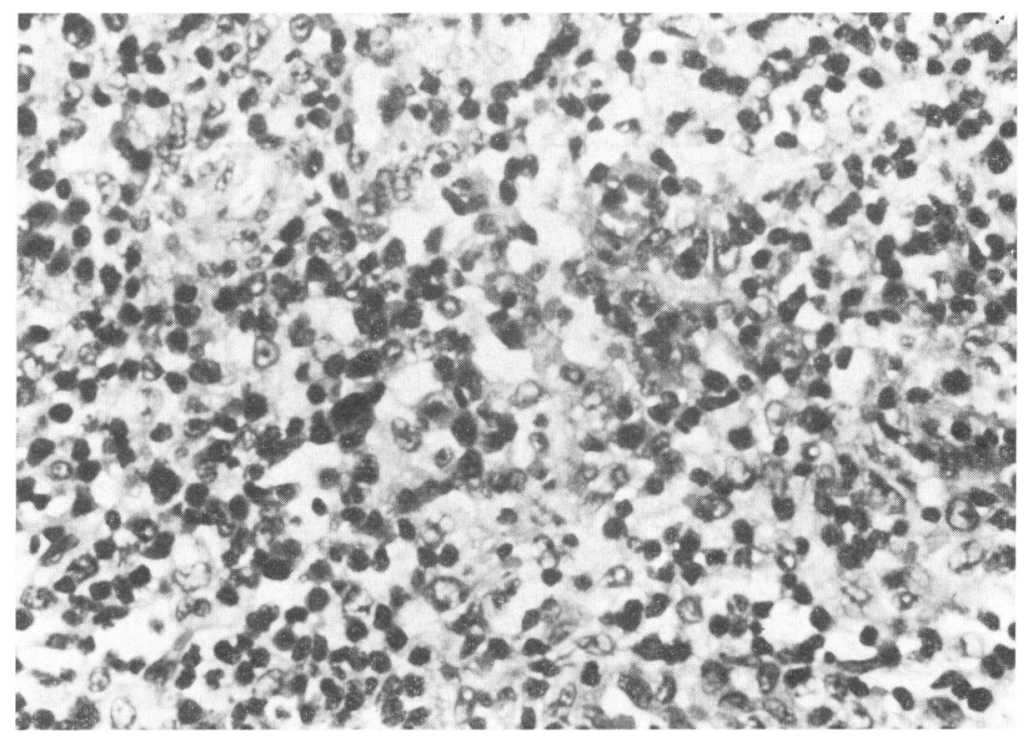

FIG. 1.-Extensive histiocytic infiltration of a lymph node from the patient. (H.E. $\times 106$.

replaced by proliferating histiocytes. There was slight histiocytic infiltration in the liver, kidneys, and in the intestinal submucosa. Lymphoid tissue in the gut also showed marked lymphocyte depletion, but lymphoid follicles were present in the tonsils and occasionally in the intestinal submucosa. The lungs showed extensive areas of consolidation and collapse. Pneumocystis carinii cysts were found.

The pathological diagnoses were acute differentiated histiocytosis (Letterer-Siwe disease), Pneumocystis carinii infection, lymphocyte depletion (primary or secondary ?).

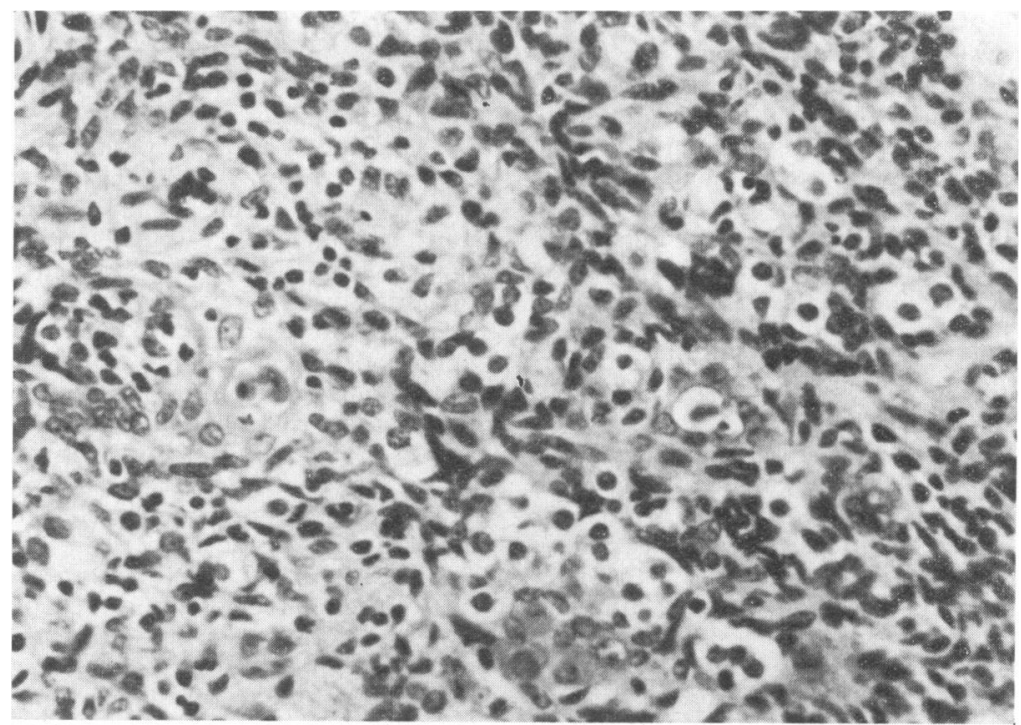

FIG. 2.-Marked lymphocytic depletion of the thymus which is composed largely of reticular cells. Occasional Hassall's corpuscles are present. (H.E. $\times 106$. 


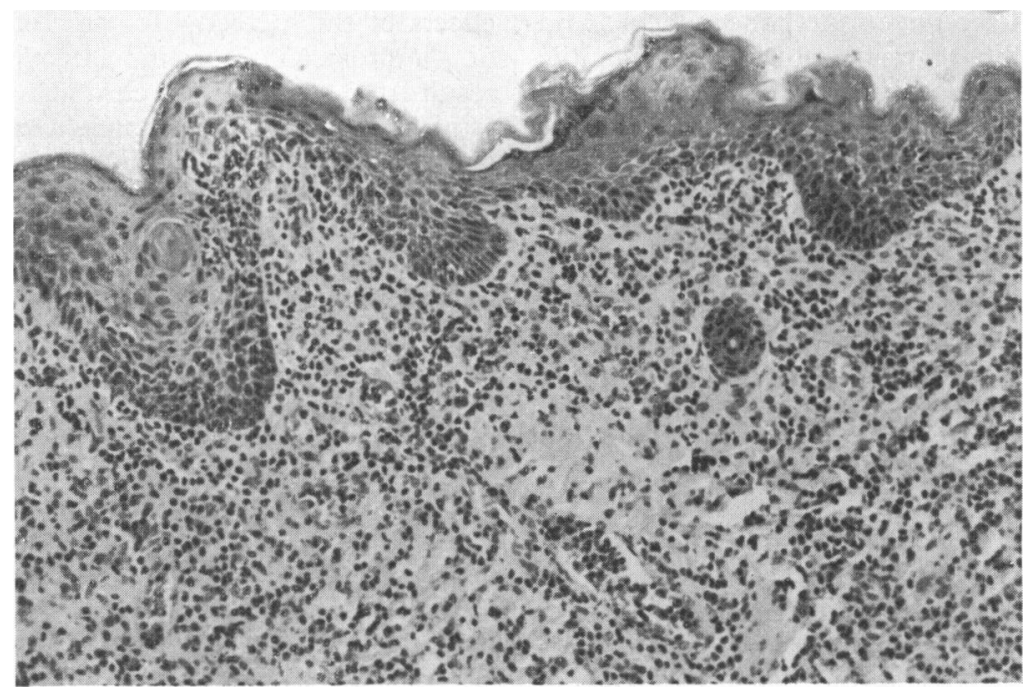

FIG. 3.-Infiltration of the upper dermis by mononuclear histiocytes. (H.E. $\times 26$.)

\section{Discussion}

The presenting clinical picture in the patient of widespread eruption, persistent diarrhoea, bacterial infection, and failure to thrive corresponded very well with that of 2 infants described by Miller $e t$ al. (1968) and Jacobs and Miller (1972). Like theirs, her serum and those of one member of each of the three previous generations were defective at opsonizing yeast for phagocytosis by normal polymorphonuclear leucocytes. Miller and his colleagues suggested that this syndrome was identical with that described by Leiner (1908), but it is clear that he did not describe a single entity, and his patients did not have many bacterial infections. In spite of this, such an eruption in infancy should be regarded as an indication for the opsonization test, because of the reported benefit of plasma infusion.

The nature of the defect is not yet clearly established. We followed Miller in using the simple yeast phagocytosis test for opsonization. The function is complicated and may involve antibody and complement, at least as far as the third component. It is possible that this test entails activation of the alternative pathway of complement directly without antibody participating, in view of the fact that zymosan, a yeast extract, will do this. It is possible that this function test could be defective because of more than one defect. Miller and Nilsson (1970) ascribed the defect in Miller's first family to functionally defective C5, despite normal concentrations of antigenically defined C5. This was because in vitro opsonization function was restored with either purified human $\mathrm{C} 5$ or normal mouse serum, but not with $\mathrm{C} 5$ deficient mouse serum. The total haemolytic complement was low by adult standards in the patient, but we do not know to what extent her age and disease might contribute to this, and the complement components of her mother, who was also defective for opsonization, were quite normal. Opsonization depends on a chain of functions, including antibody as well as the complement system, so several different defects could cause defective opsonization. Further studies in this and other families with such an opsonizing defect are being made, and at present it seems wise to consider it as a defect somewhere in this system. Indeed, such an abnormal function might be due to different defects in different families; nevertheless, whole plasma would be an appropriate reconstitution. Fresh plasma infusion in the patient led to some evidence of improvement, both clinically and by test, but the clinical improvement was less than that described by Miller She later deteriorated again and died with septicaemia and pneumocystis. At necropsy there was histiocytic infiltration consistent with Letterer-Siwe disease, and depletion of lymphocytes from the lymphoid tissue.

We, like Miller, found a familial opsonization defect. The similar findings, worst in the grandfather, over four generations with normal values in the spouses suggest a dominant inheritance as in Miller's first family, though his second one sug- 
gested autosomal recessive inheritance (Jacobs and Miller, 1972). There was no history of infantile dermatitis and diarrhoea in other members of our family, and the good health of some carriers of the gene suggest a gene with a wide variation of expression. An alternative hypothesis is of co-dominant inheritance of the relevant factor in functionally normal and functionally abnormal form (Rosen and Alper, 1973).

The other members of Miller's families with this defect have been healthy, so the chronic osteomyelitis in the grandfather is of particular interest. It is presumably related to the defect, and the death from septicaemia in the great-great-uncle may well be also. The other great-great-uncle with osteomyelitis had normal opsonization; his infection may well have been a coincidence since such an injury in the preantibiotic era often led to infection and amputation. It is possible that our patient's illness was so much more severe than other members of her family with this defect because she had a primary specific cell-mediated immunodeficiency as well. The scarcity of lymphocytes at necropsy points this way, but this could be secondary to extreme malnutrition or to lymphocyte loss through the skin or gut, which themselves could be secondary to the opsonizing defect. Pneumocystis infection of the lung is usually associated with cellmediated immunodeficiency, but this could be secondary too. Immunoglobulin concentrations exclude typical severe combined immunodeficincy; the high lymphocyte counts and the positive though weak PHA response are somewhat against isolated cell mediated-immunodeficiency but do not exclude it. The subnormality of the PHA response could well be secondary to her generally ill state by the time it was tested. The presence of some Hassall's corpuscles in the thymus is unlike typical severe combined immunodeficiency, but they seemed sparse for typical secondary thymus atrophy, and partial forms of primary combined immunodeficiency are increasingly being recognized. If there were two primary defects here, one would presumably be dominant and the other autosomal recessive. We are not aware of any other patients with two independent primary immunodeficiency diseases but it will presumably happen some time. On the whole we prefer the view that with her, too, the specific immunodeficiency features were secondary. No necropsy has been reported in Miller's diagnosed case, but the sib with a similar syndrome reported by Jacobs and Miller (1972) had a small thymus, which they regarded as a secondary effect.

Environmental factors, intrauterine and extrauterine, could also explain the wide range of effects of this defect. In view of the early onset of symptoms, intrauterine infection, which could result from symptomless chronic maternal infection associated with her immunodeficiency, is a possibility. The antiviral antibodies studied did not provide evidence for this.

The infiltration with histiocytes, so extensive as to lead to a histological diagnosis of Letterer-Siwe disease, could also be ascribed to immunodeficiency, since lymphoid neoplasia is common in immunodeficient patients (Gatti and Good, 1971). Histiocytosis has been described in association with severe combined immunodeficiency (Cederbaum et al., 1972) and Barth et al., (1972) have described a familial incidence with some evidence of immunodeficiency. This association raises the question whether it is a malignant process or an extreme overproliferation of reactive cells in an immunodeficient subject, or both. This question also applies to sporadic and familial histiocytosis generally (Freundlich et al., 1972). Immunodeficiency other than cell mediated could also produce such effects.

Another explanation of the association between infiltration with histiocytes and possible cell mediated immunodeficiency could be graft versus host disease, resulting from the blood and fresh plasma infusions, since this may also be associated with extreme histiocytosis (Hathaway et al., 1965; Soothill, Kay, and Batchelor, 1971); Kadowaki et al., (1965) reported this as occurring apparently as a result of surviving maternal cells. This possibility underlines the importance of precise diagnosis before plasma or whole blood treatment is started in a patient with possible immunodeficiency. The nature of the rash and the absence of hepatsoplenomegaly early in our patient's disease makes it likely that the histiocytosis was a secondary event, perhaps occurring at the time of the lymphocytosis, eosinophilia, and clinical deterioration, but we cannot conclude which of these possible mechanisms explains it.

The association of this defect with chronic osteomyelitis in this family raises the possibility that it may underly a wider range of infective illness than the syndrome described by Miller.

We are grateful to Dr. P. R. Evans for his advice, and tc Professor P. J. Lachmann for the haemolytic complement determinations.

\section{REFRENCES}

Barth, R. F., Vergara, G. G., Khurana, S. K., Lowman, I. T, and Beckwith, J. B. (1972). Rapidly fatal familial histiocytosis associated with eosinophilia and primary immunological deficiency. Lancet, 2, 503. 
Berry, C. L. (1970). Histiopathological findings in the combined immunity-deficiency syndrome. Fournal of Clinical Pathology, 23, 193.

Cederbaum, S. D., Niwayama, G., Stiehm, E. R., Neerhout, R. C., Ammann, A. J., and Berman, W. (1972). Combined immunodeficiency manifested by the Letterer-Siwe syndrome. Pediatric Research, 6, 379.

Freundlich, E., Amit, S., Montag, Y., Suprun, H., and Nevo, S. (1972). Familial occurrence of Letterer-Siwe disease. Archives of Disease in Childhood, 47, 122.

Gatti, R. A., and Good, R. A. (1971). Occurrence of malignancy in immunodeficiency diseases. Cancer, 28, 89.

Jacobs, J. C., and Miller, M. E. (1972). Fatal familial Leiner's disease: a deficiency of the opsonic activity of serum complement. Pediatrics, 49, 225.

Hathaway, W. E., Githens, J. H., Blackburn, W. R., Fulginiti, V., and Kempe, C. H. (1965). Aplastic anemia, histiocytosis and erythrodermia in immunologically deficient children. New England fournal of Medicine, 273, 953.

Kadowaki, J., Thompson, R. I., Zuelzer, W. W., Woolley, P. V., Brough, A. J., and Gruber, D. (1965). XX/XY lymphoid chimaerism in congenital immunological deficiency syndrome with thymic alymphoplasia. Lancet, 2, 1152.
Leiner, C. (1908). Uber Erythodermia desquamativa, eine eigenartige universelle Dermatose der Brustkinder. Archiv für Dermatologie und Syphilis, 89, 163.

Miller, M. E., and Nilsson, U. R. (1970). A familial deficiency of the phagocytosis-enhancing activity of serum related to dysfunction of the fifth component of complement (C5). New England fournal of Medicine, 282, 354.

Miller, M. E., Seals, J., Kaye, R., and Levitsky, L. C. (1968). A familial, plasma-associated defect of phagocytosis. A new cause of recurrent bacterial infections. Lancet, 2, 60,

Rosen, F. S., and Alper, C. A. (1973). Disorders of the complement system. Immunological Disorders in Infants and Children, p. 289 . Ed. by E. R. Stiehm and V. A. Fulginiti. Saunders, Philadelphia.

Soothill, J. F., Kay, H. E. M., and Batchelor, J. R. (1971). Graft restoration of primary immunodeficiency. Cell Interactions and Receptor Antibodies in Immune Responses, p. 41. Ed. by O. Makela, A. M. Cross, and T. U. Kosunen. Academic Press, New York.

Correspondence to Professor J. F. Soothill, Department of Immunology, Institute of Child Health, 30 Guilford Street, London WC1N IEH. 